\title{
Microaggressions on Campus: An Examination of Student Perceptions
}

\author{
Kirsten L. Witherup* and P.J. Verrecchia
}

York College of Pennsylvania, USA

\begin{abstract}
Creating and maintaining a positive school climate is paramount for student well-being. Microaggressions, or subtle forms of prejudice, in the classroom setting can present a barrier to cultivating such a climate and contribute to a host of negative consequences for impacted students. This study explores student perceptions of the prevalence and types of microaggressions at a private, liberal arts college in South-Central Pennsylvania. Data from student surveys will be examined to develop a better understanding of this topic and generate discussions about maintaining a positive and inclusive school climate that welcomes diversity.
\end{abstract}

Keywords: Microaggressions, School Climate, Campus Diversity, School Safety.

\section{INTRODUCTION}

Recently there has been much written about, and perhaps even more discussion on, microaggressions. Microaggressions, according to Derald Sue (2010) who (literally) wrote the book on the subject, are "the brief and commonplace daily verbal, behavioral, and environmental indignities, whether intentional or unintentional, that communicate hostile, derogatory, or negative racial, gender, and sexual orientation, and religious slights and insults to the target person or group" (p. 3). The term goes back to the 1970s when Chester Pierce, a Harvard professor of education and psychiatry, coined it (Campbell \& Manning, 2014). Pierce wrote..."The subtle, cumulative mini-assault is the substance of today's racism" and that "The black must be taught to recognize...microaggressions and construct his future by taking appropriate action at each instance of recognition" (1974, p. 516). Microaggressions has become more used recently due to slights, real or perceived, that are encountered in everyday life, and the term used by academics to call attention to the "subtle ways that racial, ethnic, gender and other stereotypes can play out painfully in an increasingly diverse culture" (Vega, 2014, para. 8).

Examples of these subtle prejudices include a college professor using mainly male sources and no works by homosexual authors, when people say "mankind," saying "him" instead of "him or her," and using the term "mother and father" (it is homophobic) (Etzioni, 2014). Other examples include asking an Asian-American about their ethnic origin, and complimenting a Latino's ability to speak English without an accent (Vega, 2014); telling someone that they are a credit to their race (Sue, Nadal, Capodilupo,

*Address correspondence to this author at the York College of Pennsylvania, USA; Tel: 717-849-1633; E-mail: kwitherup@ycp.edu
Lin, Torino \& Rivera, 2008); a woman clutching her purse when a person of color walks by (Nadal, Sriken, Davidoff, Wong \& McLean, 2013); a professor correcting a student's use of the word "Indigenous" by changing it to lower case (Flaherty, 2013); saying that the most qualified person should get the job (Sue, Lin, Torino, Capodilupo \& Rivera, 2009); and staring at a homosexual couple's pubic display of affection (Boysen, 2012).

While the examples are possibly endless, some question how much of these perceived slights is aggressive and how much is micro (Vega, 2014). John McWhorter (2014) states that it is "comforting that the term is at least microaggressions" in that "we are dealing with something smaller and less starkly egregious than name-calling and formal exclusion" (para. 8). Others are more blunt in their criticism of microaggressions. Kenneth Thomas (2008) went so far as to call microaggressions "macrononsense" (p. 274). He takes direct aim at an article (and presentation of the article at a conference) by Sue in 2007 on microaggressions, calling it "pure nonsense" (2008, p. 274). While Thomas (2008) does not deny that indignities take place in normal conversation, he worries that "the restrictions on normal human interaction recommended by Sue and his associates could have a chilling effect on free speech" (p. 274). Further, he calls being insulted when someone gives you a compliment (i.e., says you are articulate), "a bit pathological" (2008, p. 274). Schacht (2008) feels that the impact of small indignities has been blown out of proportion, and he feels that microaggressions are not necessarily evidence of underlying racist attitudes. Harris (2007), who was also in the audience for Sue's aforementioned presentation, is concerned that talking about perceived slights would be the dissemination of "biases and self-interests" and does not advance psychology as an "evidence-based science" (p. 276). 
Finally, Campbell and Maning (2014) suggest that the focus on microaggressions by "campus activists" is creating a "victimhood culture" which is distinct from the "dignity cultures of the past" (p. 692 [Emphasis in original]).

Despite the fact that much has been written (and argued) about microaggressions, there is a lack of empirical research on the subject. The purpose of this study is to survey college students to examine the prevalence and types of microaggressions on campus today. Although microaggressions can happen anywhere, we chose to survey college students because most of the discussion around microaggressions appears to be happening in college classrooms. This could be due to the fact that the number of minority students (racial and ethnic) in both universities and colleges is higher than ever (American Council on Education, 2005), as well as the number of racial groups on campus stating that they face insults that are unintentional (Bourke, 2010). According to the American Council on Education (2016), over 70 percent of college freshmen and almost three-quarters of college seniors often or very often have discussions with people of another race or ethnicity. This would, seemingly, increase the probability of unintentional slights. In addition, some (see Delgado \& Stefancic, 2017) see microaggressions as "One of the central issues in the campus-climate controversy" (p. 1,919). One tends to hear discussions and complaints about microaggressions more on colleges and universities in America (Campbell \& Manning, 2014).

\section{REVIEW OF THE LITERATURE}

\section{Defining Microaggressions}

As defined above, microaggressions are "the brief and commonplace daily verbal, behavioral, and environmental indignities, whether intentional or unintentional, that communicate hostile, derogatory, or negative racial, gender, and sexual orientation, and religious slights and insults to the target person or group" (Sue, 2010, p. 3). Sue and colleagues (Sue, Capodilupo, Torino, Bucceri, Holder, Nadal \& Esquilin, 2007) further break down microaggressions into three different types. Microassaults are blatant, conscious attempts to insult or demean and include racial epithets and sexual harassment. People engaging in microinsults might not even be aware that they have said something that could be interpreted in a negative way. An example of a microinsult would be complimenting a black person for being well spoken.
Finally, microinvalidations deny the experiences of a marginalized group. An example is if someone were to say, "When I see you I don't see color" to a person of color.

\section{Experiences with Microaggressions}

Research on student experiences with microaggressions on college and university campuses illustrates that discrimination, prejudice, and stereotypes are rather common occurrences. In fact, student reports of microaggressions is approximately 50\% (Biasco, Goodwin, \& Vitale, 2001; D'Augelle \& Hershberger, 1993; Fisher \& Hartman, 1995, as cited in Boysen, 2012). While these reports largely focus on student experiences with race-related microaggressions, other types of bias have also been explored (e.g., sexual orientation microaggressions).

\section{Racial Microaggressions}

In 2009, Sue and colleagues conducted focus group interviews 14 students who "self-identified as a person of color" (p. 183). The purpose of these interviews was to determine if, with the increasing diversity of college classrooms, microaggressions exist in academia and if so whether they lead to "difficult dialogues about race" (Sue et al., 2009, p. 184). Sue and colleagues found four themes in their study. The first was "ascription of intelligence" which is a microaggression where White people attribute a degree of intelligence to a person of color. This was reported by a Black student who felt a White student had talked down to them (assuming they were not intelligent), as well as by an Asian student who said that White students assumed they were good in math and science and worked hard in school (Sue et al., 2009). A second theme was "denial of racial reality," which was White students "rejecting dismissing or invalidating the student of color's racial reality" (Sue et al., 2009, p. 16). "Assumption of criminality" was a third theme found in the interviews, which was especially the case for Black students. The fourth theme was "alien in own land," which is a microaggression that depicted a person of color's (in this case, primarily the Asian students) group as "perpetual foreigners." (Sue et al., 2009 p. 186). This theme manifested itself when White students assumed Asian students could not speak English.

Booker (2009) also conducted a focus group as well as individual interviews of six African American female college students to develop a greater understanding about how experiences with microaggressions are 
related to classroom dynamics and peer interactions. Findings revealed challenges associated with professors and classmates (Booker, 2009). For example, the majority of participants expressed that blatant microaggressions, or experiences with more subtle comments - comments that were off-putting or rude, were attempts to undermine their class performance. Additionally, when discussing specific course topics, undergraduate women of color felt that they were expected to "represent their race" (Booker, 2009). Students reported that they wanted faculty and classmates to be more inviting with regard to class participation - not just when the conversation focused on race.

In 2014, Clark and colleagues explored six Aboriginal undergraduates' experiences with racerelated microaggressions. From this work, five themes emerged: 1) "encountering expectations of primitiveness", 2) "enduring unconstrained voyeurism", 3) "experiencing curricular elimination or misrepresentation", 4) "living with day-to-day cultural and social isolation", and 5) "withstanding jealous accusations" (Clark, Kleiman, Spanierman, Isaac, \& Poolokasingham, 2014, p. 112). Some themes that emerged were consistent with previous literature. For instance, "withstanding jealous accusations" (e.g., misinformation about law and policy) was related to the work of Hill and colleagues (2010) that discussed the "myth of meritocracy [perpetrated by] people of dominant culture [who] believe that marginalized peoples receive undeserved rewards due to their race or ethnicity" (as cited in Clark et al., 2014, p. 120). Other themes, however, were unique to the current study and expanded upon previous work on racial microaggressions. The "experiencing curricular elimination or misrepresentation" theme, for instance, was characterized by Aboriginal communities being misrepresented, overlooked, or underrepresented, which was similar to findings among American Indian students and Fist Nations students in various classroom settings (Clark et al., 2014, p. 119).

While classrooms have been cited by students as the most common location where bias has emerged (Marcus et al., 2003; Rankin, 2003, as cited in Boysen, 2012), both subtle and blatant microaggressions can occur anywhere on campus. Harwood, Browne Huntt, Mendenhall, and Lewis (2012) examined experiences with microaggressions for students of color (i.e., African American, Latino, and Native American students) in residence halls - places where students spend a considerable amount of time. Four distinct themes emerged from the more than 70 race-related microaggressions identified: 1) "denial and minimization of racism", 2) "racial jokes and verbal comments", 3) racial slurs written in shared spaces", and 4) "segregated spaces and unequal treatment" (Harwood et al., 2012, p. 159). These themes, for instance, included examples of segregated residence halls (university housing that was predominantly minority students) and differential treatment/policies for students assigned to these living areas.

\section{Sexual Orientation Microaggressions}

Sue (2010) defined sexual orientation microaggressions as "subtle discrimination in the form of verbal, behavioral, and environmental slights and indignities" (as cited in Platt \& Lenzen, 2013, p. 1011). Although overt discriminatory behavior has become less acceptable, Platt (2013) suggests that subtle forms of discrimination experienced by sexual minority groups continue to be commonplace. Using data collected from a focus group of twelve non-heterosexual college students, Platt and Lenzen (2013) identified seven types of sexual orientation microaggressions. Five of these themes were consistent with the work of Sue (2010) (i.e., Endorsement of Heteronormative Culture, Homophobia, Heterosexist Language Terminology, Oversexualization, and Sinfulness), and revealed that sexual minorities experience a range of discrimination, such as bias and harmful stereotypes. The two new themes that emerged (Microaggressions as Humor and Undersexualization), according to Platt and Lenzen (2013), highlight a potential shift in the types of sexual orientation microaggressions that students experience.

\section{Consequences of Microaggressions}

Little is known about the unfavorable consequences, academic and otherwise, for students who experience microaggressions that are racial or related to sexual orientation. However, the small body of existing research has highlighted several examples of these negative effects. For example, research finds that Black students who experience microaggressions in the academic setting can be adversely impacted in a number of ways. Microaggressions can hinder academic success and increase that likelihood that students withdraw from academic pursuits altogether (as cited in Mercer, Zeigler-Hill, Wallace, \& Hayes, 2011). Furthermore, microaggressions have been found to have deleterious effects on the physical and mental health of Black students, such as increased anxiety and depression symptoms (Hollingsworth et al., 
2017; Solórzano, Ceja, \& Yosso, 2000), binge drinking events and alcohol-related consequences (Hollingsworth et al., 2017), as well as suicidal ideations (Hollingsworth et al., 2017).

\section{Coping Mechanisms and Microaggressions}

Although microaggressions, real or perceived, can impact students differently, individuals or groups who are targeted by these behaviors, either intentionally or unintentionally, may employ a number of coping mechanisms (positive or negative) to deal with the situation. For instance, Lewis, Mendenhall, Harwood, and Browne Huntt (2013) identified five coping strategies in their research on gendered racial microaggressions among Black female students in a college setting. These strategies were categorized into one collective coping strategy (i.e., "Leaning on One's Support Network"), two resistance coping strategies (i.e., "Resisting Eurocentric Standards of Beauty" and "Using One's Voice as Power"), and two self-protective coping strategies (i.e., "Becoming a Black Superwoman" and "Becoming Desensitized and Escaping"). While most women reported using a combination of these strategies to combat gendered racial microaggressions, Lewis et al. (2013) highlighted the importance of both power and stress in the coping process for Black women.

Research has suggested that counterspaces are one option for coping with race-related stress resulting from racial microaggressions. These spaces can be described "as sites where deficit notions of people of color can be challenged and where a positive collegiate racial climate can be established and maintained" (as cited in Grier-Reed, 2010, pp. 182-183). Counterspaces provide an academic and social setting for students to cope with microaggressions, and they have been identified as imperative with regard to the academic survival of Black students (Grier-Reed, 2010; Solorzano, Ceja, \& Yosso, 2000).

\section{Campus Climate and Microaggressions}

Creating and maintaining a positive school climate is paramount for student well-being. This climate is marked by a teaching and learning environment that can foster positive student outcomes, such as academic achievement, and decrease negative student outcomes, such as absenteeism (Thapa, Cohen, Guffey, \& Higgins-D'Alessandro, 2013). Subtle forms of prejudice in the classroom or other campus settings present a barrier to creating a positive and inclusive school climate that welcomes diversity (Boysen, 2012). Such a barrier highlights the potential for a myriad of negative consequences among students who experience microaggressions. And, as stated above, some (see Delgado \& Stefancic, 2017) see microaggressions as "One of the central issues in the campus-climate controversy" (p. 1,919).

\section{METHODS}

A survey was created and distributed at private, liberal arts college in South-Central Pennsylvania ${ }^{1}$. Every student at the school received the survey via email using Qualtrics research software. The survey was a combination of demographic questions (e.g., age, sex, and political beliefs) and three questions that dealt with microaggressions in the college classroom. The college has approximately 4,500 students (undergraduate and graduate) who are mostly White $(78.7 \%)$ and female (53.9\%). Respondents were recruited from September 12, 2018 through October 8, 2018. The data from students were collected on October 11, 2018, and IBM SPSS software was used to analyze the data.

\section{Participants}

Three hundred and thirty-three $(\mathrm{N}=333)$ students completed surveys. The average age of our sample was 20.76 years $(S D=4.80)$. Our sample was majority White $(83.5 \%)$, full time students $(96.4 \%)$, and female $(59.2 \%)$. Most of our students $(43.5 \%)$ described themselves politically as a mix of liberal and conservative, while slightly more students (30.6\%) described themselves as very liberal or liberal than very conservative or conservative $(25.8 \%)$. Table 1 provides the demographic data for our variables.

\section{RESULTS}

To examine the prevalence and types of microaggressions in the classroom we asked our participants to respond to three Likert scale statements, all of which were coded as strongly disagree (1), disagree (2), neither agree nor disagree (3), agree (4), and strongly agree (5). The first stated, "According to Sue et al. (2010), microassaults include verbal derogation of a specific group, discriminatory behavior and avoidance or exclusion. Based on this definition

\footnotetext{
${ }^{1}$ The authors reached out to several other universities to distribute surveys, but the response rate was so low $(n=34)$ that they were not included in the analysis.
} 
Table 1: Participant Demographics $(N=333)$

\begin{tabular}{|c|c|c|}
\hline Demographic & Frequency & Percent \\
\hline \multicolumn{3}{|l|}{ Age } \\
\hline $18-22$ & 300 & 90.1 \\
\hline $23-27$ & 17 & 5.1 \\
\hline $28-32$ & 6 & 1.8 \\
\hline 33-37 & 4 & 1.2 \\
\hline 38 and older & 6 & 1.8 \\
\hline \multicolumn{3}{|l|}{ Sex } \\
\hline Male & 136 & 40.8 \\
\hline Female & 197 & 59.2 \\
\hline \multicolumn{3}{|l|}{ Race } \\
\hline American Indian or Alaskan Native & 1 & 0.3 \\
\hline Asian & 7 & 2.1 \\
\hline Black & 17 & 5.1 \\
\hline Latino/a & 11 & 3.3 \\
\hline Native Hawaiian or other Pacific Islander & 1 & .3 \\
\hline White & 278 & 83.5 \\
\hline Other & 18 & 5.4 \\
\hline \multicolumn{3}{|l|}{ Academic Major } \\
\hline Natural Sciences & 49 & 14.7 \\
\hline Social Sciences & 65 & 19.5 \\
\hline Humanities & 29 & 8.7 \\
\hline Engineering & 33 & 9.9 \\
\hline Business & 61 & 18.3 \\
\hline Nursing & 35 & 10.5 \\
\hline Education & 20 & 6.0 \\
\hline Other & 41 & 12.3 \\
\hline \multicolumn{3}{|l|}{ Year in School } \\
\hline Freshman & 100 & 30.1 \\
\hline Sophomore & 70 & 21.0 \\
\hline Junior & 62 & 18.6 \\
\hline Senior & 93 & 27.9 \\
\hline Graduate Student & 8 & 2.4 \\
\hline \multicolumn{3}{|l|}{ Student Status } \\
\hline Full time & 321 & 96.4 \\
\hline Part time & 12 & 3.6 \\
\hline \multicolumn{3}{|l|}{ Political Beliefs } \\
\hline Very liberal & 30 & 9.0 \\
\hline Liberal & 72 & 21.6 \\
\hline Mix of liberal and conservative & 145 & 43.5 \\
\hline Conservative & 71 & 21.3 \\
\hline Very conservative & 15 & 4.5 \\
\hline
\end{tabular}


Table 2: Microaggressions Statements

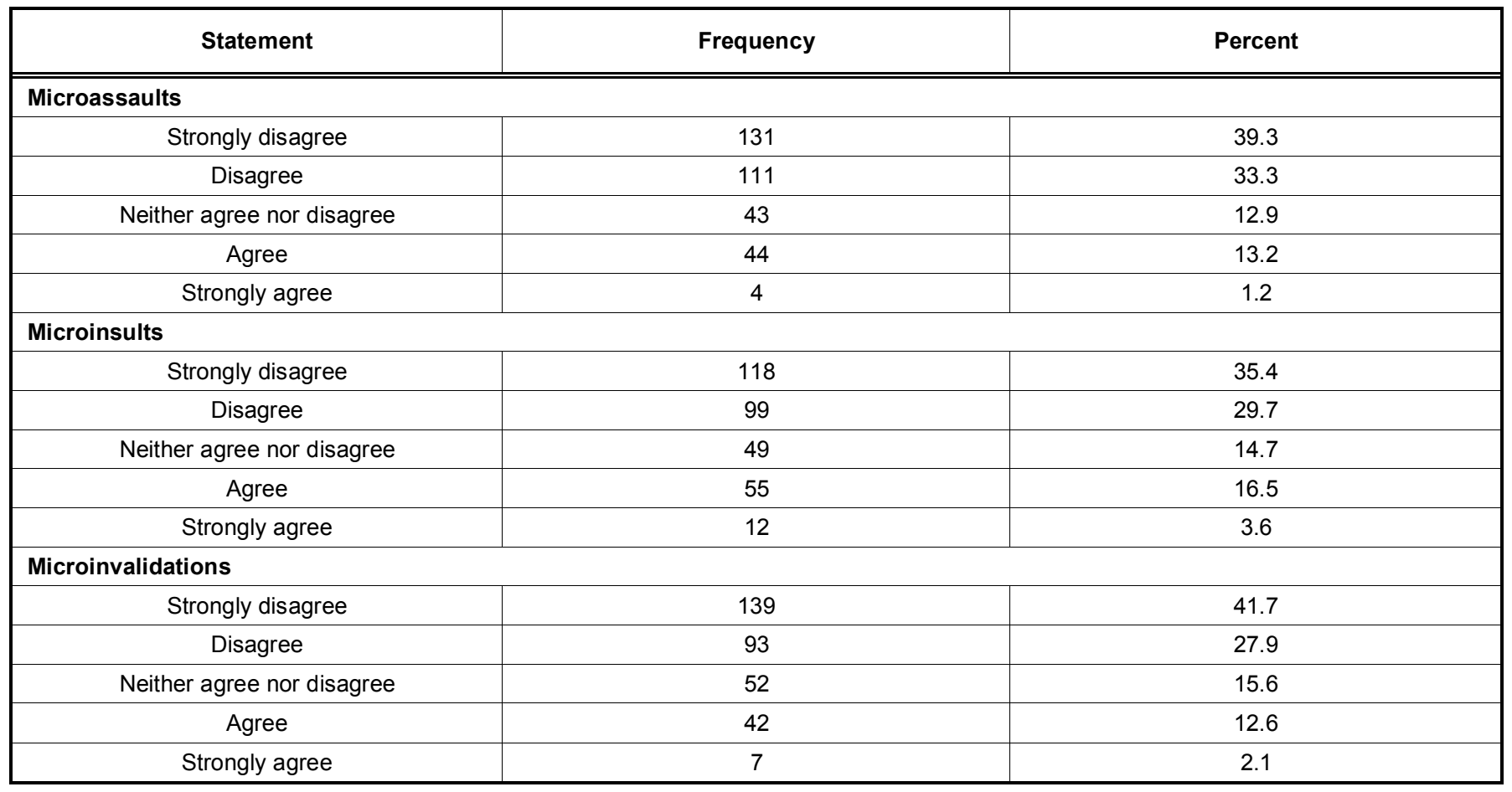

please respond to the following statement: Microassaults have been a problem in my classes in the last academic year." The majority (72.9\%) of our students strongly disagreed or disagreed with this statement. We then asked our students to respond to the following statement: "According to Sue et al. (2010), microinsults include assumptions about intelligence or ability, viewing other cultures as abnormal, and other stereotypical notions. Based on this definition please respond to the following statement: Microinsults have been a problem in my classes in the last academic year." The majority, though fewer $(65.2 \%)$, of our students strongly disagreed or disagreed with this statement. We then asked our students to respond to the following statement: "According to Sue et al. (2010), microinvalidations include characterizing minorities as foreigners or as professing color blindness. Based on this definition please respond to the following statement: Microinvalidations have been a problem in my classes in the last academic year." The majority $(69.7 \%)$ of our students strongly disagreed or disagreed with this statement. We combined these results to create a microaggression index to use as our dependent variable since, according to Sue et al. (2020), microaggressions are made up of microassaults, miroinsults, and microinvalidations. The index would range from a low of 3 (strongly disagree with each statement) to a high of 15 (strongly agree with each statement). The results for each Likert scale statement can be found in Table 2 . The mean score on the microaggression index was 6.32 ( $S D=3.13)$. The Cronbach's alpha for this index was a robust .909 .

The dependent variable was then dichotomized in order to run a logistic regression model. The goal of this study is to determine whether there are differences in perceived microaggressions in the college classroom based on demographic characteristics such as race, age, academic major, political beliefs, and so on. The dichotomized index predicts the probability of membership in terms of how problematic (problematic or not) microaggressions are in the college classroom. The aim of this study is to learn what combinations of our independent variables would predict the probability of perceiving microaggressions and seeing them as a problem. Logistic regression predicts and explains relationships between a binary dependent variable and one or more variable measured at any level (Heiman, 2014; Tabachnick \& Fiddell, 2007; Weisburd, 1998).

Regression results for the microaggression model indicate that the overall model was statistically reliable (Model $X^{2}(8)=58.480, p<.001$ ). Our microaggression model correctly predicted $84.4 \%$ of the responses. This model revealed that non-white $(\beta=-.288 \mathrm{p}<.05)$, students in higher grades $(\beta=.573, p<.01)$, and who 
Table 3: Logistic Regression Results Microaggressions

\begin{tabular}{|c|c|c|c|c|c|c|}
\hline Variable & B & S.E. & Wald & df & Sig. & $\operatorname{Exp}(B)$ \\
\hline Race $^{*}$ & -.288 & .136 & 4.507 & 1 & .034 & .750 \\
\hline $\mathrm{Age}^{\mathrm{A}}$ & -.221 & .118 & 3.517 & 1 & .061 & .802 \\
\hline $\operatorname{Sex}^{\mathrm{A}}$ & .602 & .364 & 2.730 & 1 & .099 & 1.826 \\
\hline Political Beliefs ${ }^{* \star *}$ & -.997 & .183 & 29.637 & 1 & .000 & .369 \\
\hline Academic Major & .092 & .071 & 1.675 & 1 & .196 & 1.096 \\
\hline Year in School** & .573 & .190 & 9.067 & 1 & .003 & 1.773 \\
\hline Student Status & .217 & 1.373 & 3025 & 1 & .874 & 1.242 \\
\hline Constant & 4.101 & 2.665 & 2.368 & 1 & .124 & 60.402 \\
\hline Model Chi-Square & 58.480 & & & & & \\
\hline Negelkerke $\mathrm{R}^{2}$ & .265 & & & & & \\
\hline
\end{tabular}

Note: ${ }^{*} p<.05 ;{ }^{* *} p<.01 ;{ }^{* *} p<.001 ;{ }^{A} p<.10$.

described their political beliefs as liberal $(\beta=-.997$, $\mathrm{p}<.001)$ were more likely to see microaggressions in the classroom. Non-white students $(\operatorname{Exp}(B)=.750)$ were $75 \%$ more likely than white students to see microaggressions in the classroom, juniors, seniors, and graduate students $(\operatorname{Exp}(B)=1.773)$ were almost two times more likely than freshmen and sophomores to see microaggressions in the classroom, and students who classify themselves as liberal $(\operatorname{Exp}(B)=.369)$ were about $40 \%$ more likely. The results of the model can be found in Table $3^{2}$.

\section{DISCUSSION}

This study examined student experiences with microaggressions in the classroom at a private, liberal arts college in South-Central Pennsylvania. Overall, the majority of students strongly disagreed or disagreed that microaggressions (i.e., microassaults, microinsults, and microinvalidations) have been a problem in classes in the last academic year. While these findings appear to indicate that microaggressions are in fact not a problem for this campus in particular, exploring differences in perceived microaggressions in the classroom based on demographic characteristics (e.g., academic major, age, and race) proved to be somewhat contradictory to this notion.

Specifically, logistic regression results for the microaggression model revealed that non-White students, students in higher grades (i.e., juniors, seniors, and graduate students), and students who identified as politically liberal were more likely to see

${ }^{2}$ Two variables, sex $(\beta=.602, p=.099)$ and age $(\beta=.-221, p=.061)$ approached significance. microaggressions in the classroom. With regard to race, current findings parallel previous work suggesting that racial and ethnic minority students report more frequent experiences with microaggressions in college classrooms (Bourke, 2010). Additionally, given that the majority of students in our sample are White and attend a predominately White college, these results support a body of previous work that suggests incidents of microaggressions are only pervasive in society for those who frequently experience them (e.g., racial and ethnic minorities), and that well intentioned individuals who are not targeted by microaggressions are generally unware of these offensive acts (Bell, 2002; Rowe, 1990; Sue et al., 2008; as cited in Sue et al., 2009).

The current study contributes of the paucity of previous work exploring microaggressions and student grade level as well as microaggressions and student political beliefs. We suggest that students in higher grades could be more aware of microaggressions in the classroom setting having had more exposure to coursework and dialogue dealing with diversity as well as implicit bias. It can also be argued that students who identified as politically liberal might be more socially conscious with regard to bias in their classrooms. Notably, three of the demographic characteristics lacked statistical significance. These items included age, major, and sex.

\section{LIMITATIONS AND FUTURE RESEARCH}

Despite significant findings that reinforce previous work on microaggressions and add to the existing data, it is necessary to examine potential limitations of this work. For instance, this study only includes data from one college. To develop a greater understanding of 
microaggressions on campuses, further research is needed that collects data from both colleges and universities across the United States.

Another limitation involves the racial make-up of our sample, as data are derived from predominately White respondents. From our findings, we see that reported experiences with microaggressions are different (i.e., more problematic) for minority students. As such, future research that includes a more diverse sample from more diverse campuses could impact the amount of perceived slights or insults reported by students as well as the types of microaggressions experienced.

\section{POLICY IMPLICATIONS AND CONCLUSION}

As college and university campuses become increasingly diverse and interracial interactions increase so too will the opportunities for microaggressions to occur (Sue et al., 2009). It is essential that given the reported frequency of these incidents by targeted students (Biasco, Goodwin, \& Vitale, 2001; D'Augelle \& Hershberger, 1993; Fisher \& Hartman, 1995, as cited in Boysen, 2012), as well as the related unfavorable consequences, academic and otherwise (Lewis et al., 2013; Grier-Reed, 2010; Solorzano, Ceja, \& Yosso, 2000), that more effort is spent developing an awareness and understanding of these experiences. While this study highlights that nonwhite students, students in higher grades, and students who identified as politically liberal are more likely to see microaggressions, this is only an initial step in addressing and preventing microaggressions in the classroom setting and on campus more generally. Creating and maintaining safe learning environments for all students is a task that must be addressed by the whole school community. Administrators, faculty, staff, and students must collectively be responsible for acknowledging and ameliorating bias, as the inability to perceive or ignoring such behaviors creates an unwelcoming space in the classroom setting and negative climate on campus for marginalized populations.

Or perhaps there is something else going on. In The Coddling of the American Mind: How Good Intentions and Bad Ideas are Setting Up a Generation for Failure, Lukianoff and Haidt (2018) state that many of Sue's examples of microaggressions are not evidence that the speaker holds negative stereotypes toward anyone. They concede that certain statements (such as, the most qualified person should get the job) could be interpreted as "tiny acts of aggression, rebuke, and exclusion-and sometimes that is exactly what they are" (p. 41). Lukianoff and Haidt ask whether we should be teaching students to interpret these statements as acts of microaggressions. Could the reason that freshmen don't see microaggressions while sophomores, juniors, and seniors on the same college campus do be because freshmen have not been taught yet, by faculty, that a statement they might ignore or pass off as the ramblings of an ignorant individual are actually a form of aggression? In other words, are students being indoctrinated into the world of microaggressions? One way to explore this would be to survey high school students on their views of microaggressions. Another way would be to survey professors to see how their views of microaggressions compare with those of their students.

\section{REFERENCES}

American Council on Education. 2005. College Students Today: A National Portrait. Retrieved November $5 \quad 2017$ (http://www.acenet.edu/news-room/Documents/CollegeStudents-Today-A-National-Portrait-2005.pdf).

American Council on Education. 2016. By the Numbers: Facts of Student Life. Retrieved November 5, 2017 (http://www.acenet.edu/thepresidency/columns-and-features/Pages/By-the-Numbers-Factsof-Student-Life.aspx)

Bell, Lee A. 2002. "Sincere Fictions: The Pedagogical Challenges of Preparing White Teachers for Multicultural Classrooms." Equity and Excellence in Education 35: 236-244.

https://doi.org/10.1080/713845317

Biasco, Frank, Elizabeth A. Goodwin and Kevin L. Vitale. 2001. "College Students' Attitudes Toward Racial Discrimination." College Student Journal 35: 523-528.

Blume, Arthur W., Laura V. Lovato, Bryan N. Thyken and Natasha Denny. 2012. "The Relationship of Microaggressions with Alcohol Use and Anxiety Among Ethnic Minority College Students in a Historically White Institution." Cultural Diversity \& Ethnic Minority Psychology 18(1): 45-54. https://doi.org/10.1037/a0025457

Booker, Keonya. 2016. "Connection And Commitment: How Sense of Belonging and Classroom Community Influence Degree Persistence for African American Undergraduate Women." International Journal of Teaching and Learning in Higher Education 28(2): 218-229.

Bourke, Brian. 2010. "Experiences of Black Students in Multiple Cultural Spaces at a Predominantly White Institution." Journal of Diversity in Higher Education 3: 126-135. https://doi.org/10.1037/a0019025

Boysen, Guy A. 2012. "Teacher and Student Perceptions of Microaggressions in Classrooms." College Teaching 60(3): 122129.

https://doi.org/10.1080/87567555.2012.654831

Campbell, Bradley and Jason Manning. 2014. "Microaggression and Moral Cultures." Comparative Sociology 13: 692-726. https://doi.org/10.1163/15691330-12341332

Campbell, Bradley and Jason Manning. 2018. The Rise of Victimhood Culture: Microaggressions, Safe Spaces, and the New Culture Wars. Cham, Switzerland: Palgrave Macmillan. https://doi.org/10.1007/978-3-319-70329-9

Clark, D. Anothny, Sela Kleiman, Lisa B. Spanierman, Paige Isaac, and Gauthamie Poolokasingham. 2014. "'Do You Live in a Teepee?' Aboriginal Students' Experiences with Racial Microaggressions in Canada." Journal of Diversity in Higher Education 7(2): 112-125. https://doi.org/10.1037/a0036573 
D'Augelli, Anthony R. and Scott L. Hershberger. 1993. "African American Under-Graduates on a Predominantly White Campus: Academic Factors, Social Networks, and Campus Climate." Journal of Negro Education 62: 67-81. https://doi.org/10.2307/2295400

Delgado, Richard and Jean Stefancic. 2017. "Four Ironies of Campus Climate." Minnesota Law Review 101(5): 1919-1941.

Etzoni, Amitai. 2014. Don't Sweat the Microaggressions: The Old Pitfall of New Sensitivities in Political Speech. The Atlantic, April 8. Retrieved June 22, 2017 (https://theatlantic.com/politics/archive/ 2014/04/dont-sweat-the-microaggressions/360278/).

Fisher, Bradley J. and David J. Hartman. 1995. "The Impact of Race on the Social Experience of College Students at a Predominantly White University." Journal of Black Studies 26: 117-133. https://doi.org/10.1177/002193479502600202

Flaherty, Colleen. 2013. In-class Sit-in. Inside Higher Ed, November 25. Retrieved November 5, 2017 (https://www.insidehighered.com/ news/2013/11/25/ucla-grad-students-stage-sit-during-classprotest-what-they-see-racially-hostile).

Grier-Reed, Tabitha. 2010. "The African American Student Network: Creating Sanctuaries and Counterspaces for Coping with Racial Microaggressions in Higher Education Settings." Journal of Humanistic Counseling, Education \& Development 49(2): 181188. https://doi.org/10.1002/j.2161-1939.2010.tb00096.x

Harris, Rafael S. 2007. "Racial Microaggression? How Do You Know?" The American Psychologist 63(4): 275-276. https://doi.org/10.1037/0003-066X.63.4.275

Harwood, Stacy A., Margaret B. Huntt, Ruby Mendenhall and Jioni A. Lewis. 2012. "Racial Microaggressions in the Residence Halls: Experiences of Students of Color at a Predominantly White University." Journal of Diversity in Higher Education 5(3): 159173.

https://doi.org/10.1037/a0028956

Heiman, Gary W. 2014. Basic Statistics for the Behavioral Sciences. Belmont, CA: Wadsworth.

Hollingsworth, David W., Ashely B. Cole, Victoria M. O'Keefe, Raymond P. Tucker, Chandra R. Story and LaRicka Wingate. 2017. "Experiencing Racial Microaggressions Influences Suicide Ideation Through Perceived Burdensomeness in African Americans." Journal of Counseling Psychology 64(1): 104-111. https://doi.org/10.1037/cou0000177

Lewis, Jioni A., Ruby Mendenhall, Stacy A. Harwood and Margaret B. Huntt. 2013. "Coping with Gendered Racial Microaggressions Among Black Women College Students." The Journal of African American Studies 17(1): 51-73. https://doi.org/10.1007/s12111-012-9219-0

Marcus, Ann, Larry C. Mullins, Kimberly P. Brackett, Zongli Tang, Annette M. Allen, and Daniel W. Pruett. 2003. "Perceptions of Racism on Campus." College Student Journal 37: 611-626.

McWhorter, John. 2014. 'Microaggresion' is the New Racism on Campus. Time, March 21. Retrieved June 22, 2017 (http://time.com/32618/ microaggressions-is-the-new-racism-on-campus/).

Mercer, Sterett H., Virgil Zeigler-Hill, Marion Wallace and DeMarquis M. Hayes. 2011. "Development and Initial Validation of the Inventory of Microaggressions Against Black Individuals." Journal of Counseling Psychology 58(4): 457-469. https://doi.org/10.1037/a0024937
Nadal, Kevin L., Julie Sriken, Kristin C. Davidoff, Yinglee Wong and Kathryn McLean. 2013. "Microaggressions Within Families: Experiences of Multiracial People." Family Relations 62(1): 190201. https://doi.org/10.1111/j.1741-3729.2012.00752.x

Platt, Lisa F. and Alexandra L. Lenzen. 2013. "Sexual Orientation Microaggressions and the Experience of Sexual Minorities." Journal of Homosexuality 60(7): 1011-1034. https://doi.org/10.1080/00918369.2013.774878

Rankin, Susan R. 2003. Campus Climate for Gay, Lesbian, Bisexual, and Transgender People: A National Perspective. Washington, DC: National Gay and Lesbian Task Force.

Rowe, Mary P. 1990. "Barriers to equality: The Power of Subtle Discrimination to Maintain Unequal Opportunity." Employee Responsibilities and Rights Journal 3: 153-163. https://doi.org/10.1007/BF01388340

Schacht, Thomas E. 2008. "A Broader View of Racial Microaggressions in Psychotherapy." The American Psychologist 63(4): 273. https://doi.org/10.1037/0003-066X.63.4.273

Solorzano, Daniel, Miguel Ceja and Tara Yosso. 2000. "Critical Race Theory, Racial Microaggressions, and Campus Racial Climate: The Experiences of African-American College Students." The Journal of Negro Education 69(1/2): 60-73.

Sue, Derald W. 2010. Microaggressions in Everyday Life: Race, Gender and Sexual Orientation. Hoboken, NJ: John Wiley and Sons.

Sue, Derald W., Christina M. Capodilupo, Gina C. Torino, Jennifer M. Bucceri, Aisha M. B. Holder, Kevin L. Nadal and Marta Esquilin. 2007. "Racial Microaggressions in Everyday Life: Implications for Clinical Practice." American Psychologist 62: 271-286. https://doi.org/10.1037/0003-066X.62.4.271

Sue, Derald W., Kevin L. Nadal, Christina M. Capodilupo, Annie I. Lin, Gina C. Torino and David P. Rivera. 2008. "Racial Microaggressions Against Black Americans: Implications for Counseling." Journal of Counseling and Development 86: 330338. https://doi.org/10.1002/j.1556-6678.2008.tb00517.x

Sue, Derald W., Annie I. Lin, Gina C. Torino, Christina M. Capodilupo, and David P. Rivera. 2009. "Racial Microaggressions and Difficult Dialogues on Race in the Classroom." Cultural Diversity and Ethnic Minority Psychology 15(2): 183-190. https://doi.org/10.1037/a0014191

Tabachnick, Barbara G and Linda S. Fiddell. 2007. Using Multivariate Statistics (5th ed.) Boston, MA: Allyn \& Bacon.

Thapa, Amrit., Jonathan Cohen, Shawn Guffey and Ann HigginsD'Alessandro. 2013. "A Review of School Climate Research." Review of Educational Research 83, 357-385. https://doi.org/10.3102/0034654313483907

Thomas, Kenneth R. 2008. "Macrononsense in Multiculturalism." The American Psychologist 63(4): 274-275. https://doi.org/10.1037/0003-066X.63.4.274

Vega, Tanzina. 2014. Students See Many Slights as Racial 'Microaggressions.' The New York Times, March 21. Retrieved November 2, 2017, from (http://www.nytimes.com/2014/03/22/ us/as-diversity-increases-slights-get-subtler-but-still-sting.html).

Weisburd, David. 1998. Statistics in Criminal Justice. Belmont, CA: Wadsworth.

\section{DOI: https://doi.org/10.6000/1929-4409.2019.08.10}

(C) 2019 Witherup and Verrecchia; Licensee Lifescience Global.

This is an open access article licensed under the terms of the Creative Commons Attribution Non-Commercial License (http://creativecommons.org/licenses/by-nc/3.0/) which permits unrestricted, non-commercial use, distribution and reproduction in any medium, provided the work is properly cited. 